\title{
Analisis Kinerja Jalan Dr. Angka dan Pengaruh Pemberian Median Jalan Purwokerto
}

\author{
Analysis Of Road Performance Dr. Angka and The Effect Of Giving Jalan \\ Purwokerto Median
}

\author{
Doni Putra Wibowo $^{1^{*}}$, Sulfah Anjarwati2 \\ ${ }^{1,2}$ Teknik Sipil, Fakultas Teknik dan Sains \\ Universitas Muhammadiyah Purwokerto \\ *corr-author: doniputrawibowo2@gmail.com
}

\begin{abstract}
ABSTRAK
Jalan Dr. Angka Purwokerto merupakan jalan yang cukup vital dengan tipe jalan empat lajur dua arah tanpa pemisah arah (median) dari kondisi ruas jalan yang cukup padat lalu lintas tersebut maka pemisah arah (median) dapat diterapkan guna meningkatkan kapasitas dan kinerja ruas jalan itu. Hasil analisa jalan Dr. Angka kondisi existing atau jalan tanpa median didapatkan data kejenuhan 1,56 dimana nilai tersebut melebihi batas kejenuhan yang diijinkan menurut MKJI 1997 yaitu 0,75. Sehingga kondisi ruas jalan Dr. Angka dengan nilai DS tersebut, berarti bahwa kondisi arus lalu lintasnya tidak stabil dengan kepadatan yang tinggi. Berbeda dengan jalan Dr. Angka kondisi baru, karena adanya pemisah arah (median) yang membatasi dua arah yang berlawanan, menimbulkan rendahkan kepadatan lalu lintas pada ruas jalan tersebut. Tingkat pelayanan pada jalan Dr. Angka Purwokerto mengalami peningkatan akibat perubahan geometrik dan perbaikan jalan tersebut. Berdasarkan analisa pada kondisi jalan Dr. Angka kondisi baru lebih baik dibandingkan dengan kondisi lama.
\end{abstract}

Kata kunci: Kinerja jalan, Pengaruh Pemberian Median, Kepadatan lalulintas, Tingkat Pelayanan

\section{ABSTRACT}

Dr. Angka The Purwokerto figure is a fairly vital road with a two-way four-lane road type without a direction separator (median) from the condition of the road that is quite dense of traffic, the direction separator (median) can be applied to increase the capacity and performance of the road segment. The results of the path analysis Dr. Angka Existing condition or road without median obtained saturation data 1.56 where the value exceeds the allowable saturation limit according to MKJI 1997 which is 0.75. So the condition of Dr.Angka with the DS value means that the condition of the traffic flow is unstable with high density. Different from Dr.Angka of new conditions, due to the presence of a direction separator (median) which limits the two opposite directions, causes a low density of traffic on the road. The level of service on the path of Dr. Angka Purwokerto's have increased due to geometric changes and improvements to the road. Based on the analysis of the road conditions Dr. Angka of new conditions is better than the old conditions.

Keywords: Road performance, Effect of Median Giving, Traffic Density, Service Level 


\section{PENDAHULUAN}

Dengan semakin majunya perkembangan pembangunan saat ini, kebutuhan akan penggunaan jalan sangatlah penting. Baik untuk masyarakat yang berada di perkotaan maupun di pedesaan, terlebih dalam pemenuhan perekonomian masyarakat itu sendiri yang nantinya diharapkan dapat menciptakan keselarasan dan kesejahteraan masyarakat sehingga negara Indonesia dapat maju dan dapat tercapainya tujuan pembangunan itu sendiri. Pertumbuhan ekonomi menyebabkan mobilitas seseorang meningkat melebihi sistem prasarana transportasi yang ada.

Seperti diketahui bahwa sekarang ini banyak sekali alat transportasi yang dapat digunakan, namun alat transportasi darat yang banyak dan sering digunakan oleh pemakainya. Sekarang ini pengaturan lalu lintas tidak hanya terbatas pada arus lalu lintas saja, tetapi juga dirasakan perlu diketahui hubungan dan akibat dari adanya fasilitasfasilitas transportasi pada keadaan lingkungan sekitarnya, sehingga akan sesuai dengan apa yang diinginkan. Untuk memenuhi hal-hal tersebut, setiap pihak-pihak yang berkaitan sangat dituntut kerjasamanya yang baik. Pemerintah telah merencanakan dan meningkatkan prasarana jalan yang sudah ada sedangkan pemakai jalan dituntut untuk menjaga dan memelihara jalan tersebut agar tingkat pelayanan dapat terpenuhi. Selain hal diatas perlu juga fasilitas penunjang, antara lain rambu-rambu lalu lintas, pemisah arah dan lain sebagainya. Pemisah arah (median) merupakan salah satu fasilitas yang juga berpengaruh pada karakteristik arus lalu lintas.

Penempatan median bertujuan untuk memisahkan arus dalam lalulintas yang berlawanan, sehingga efektifitas jalan dapat ditingkatkan. Jalan merupakan prasarana transportasi darat yang meliputi segala bagian jalan, termasuk bangunan pelengkap dan perlengkapannya yang diperuntukkan bagi lalulintas, yang berada pada permukaan tanah, diatas permukaan tanah, dibawah permukaan tanah atau air, serta diatas permukaan air, kecuali jalan kereta api, jalan lori, dan jalan kabel, itu sebabnya jalan merupakan hal yang sangat penting karena dengan jalan maka daerah yang satu dapat berhubungan dengan daerah yang lainnya. Untuk menjamin agar jalan dapat memberikan pelayanan sebagaimana yang diharapkan maka selalu diusahakan peningkatan-penigkatan jalan itu. Dengan bertambahnya jumlah kendaraan bermotor, hal ini menyebabkan meningkatnya jumlah arus lalulintas dengan kemampuan jalan yang terbatas. Keadaan jalan yang macet bukan merupakan hal yang baru dialami di kota-kota besar khususnya di Indonesia. Hal ini diutamakan karena bertambahnya keinginan masyarakat untuk menggunakan kendaraankendaraan bermotor pribadi untuk memenuhi aktivitas kehidupannya tanpa melihat jauh dampak yang ditimbulkan. Dengan selalu bertambahnya pengguna jalan, terutama pada jam-jam tertentu sehigga menuntut adanya peningkatan kualitas dan kuantitas suatu jalan, untuk itulah perlu adanya penelitian mengenai kapasitas jalan yang ada sehingga dapat dievaluasi dan dianalisa untuk mengantisipasi perkembangan jumlah kendaraan dan perkembangan penduduk khususnya di kota Purwokerto.

Jalan Dr. Angka yang ada di kota Purwokerto merupakan jalan yang cukup vital dengan tipe jalan 4 lajur 2 arah, dimana tidak ada pemisah jalan. Dengan kondisi jalan yang termasuk kawasan hotel, perumahan, pertokoan, sekolah, rumah sakit, tempat ibadah, dan lain sebagainya menyebabkan lalulintas jalan tersebut mengalami perkembangan sesuai dengan keadaan sekitar. Untuk itu perlu tinjauan terhadap sistem lalulintas yang ada dengan dibuatnya pemisah arah jalan. 


\section{METODE}

\section{Data Primer}

Data Primer adalah data yang diperoleh dan melakukan langsung survei di lapangan yang meliputi : Volume, Kecepatan dan Geometrik Jalan. Pada penelitian ini, survei dilakukan selama 3 (hari) hari dalam satu minggu yakni dari hari Sabtu, Minggu dan Senin. Dalam setiap kali survei, pengamatan dilakukan selama 12 (dua belas) jam yakni dari pukul 06.00 sampai pukul 18.00. Dalam pencatatan jumlah kendaraan dan kecepatan dilakukan setiap periode 15 menit.

\section{Pengambilan Data}

Dalam proses pengambilan data ini, diperlukan 6 (enam) orang surveyor, 2 (dua) orang bertugas untuk menghitung volume kendaraan dan 2 (dua) orang bertugas untuk menghitung hambatan samping dan 2 (dua) orang bertugas menghitung kecepatan kendaraan (menggunakan Traffic Counter).

\section{HASIL DAN PEMBAHASAN}

\section{Hasil Perhitungan masing-masing perbandingan}

\section{Analisis Kondisi}

Data yang diolah untuk analisis kondisi jalan baru yaitu data survei yang mempunyai volume lalu lintas tertinggi pada hari sabtu 15 desember 2018 pada dua arah pukul 17.0018.00 untuk arah barat - timur dan 16.00-17.00 untuk timur - barat.

2. Arus Lalu Lintas Total

Kondisi baru jalan Dr. Angka Purwokerto merupakan tipe jalan empat lajur terbagi (4/2 D) sehingga dapat diketahui nilai emp untuk kendaraan, yaitu:

- Kendaraan Ringan (LV) : 1,0

- Kendaraan Berat (HV) : 1,2

- Sepeda Motor (MC) : 0,25

Hasil perhitungan kondisi existing pada jam puncak dapat dilihat pada Tabel 1, sedangkan Hasil perhitungan kondisi baru pada jam puncak dapat dilihat pada Tabel 2.

Tabel 1. Hasil perhitungan kondisi existing pada jam puncak

\begin{tabular}{lcccccccc}
\hline Hari, & & (LV) & & (HV) & & (MC) & & Q \\
Tanggal & waktu & 1,0 & LV & 1,3 & HV & 0,40 & MC & smp/jam \\
\hline Sabtu, 15 & $12.00-$ & 1,0 & 1244 & 1,3 & 37 & 0,40 & 2019 & 2.099 \\
$\begin{array}{l}\text { Desember } \\
2018\end{array}$ & 13.00 & & & & & & & \\
\hline
\end{tabular}

Tabel 2. Hasil perhitungan kondisi baru pada jam puncak

\begin{tabular}{|c|c|c|c|c|c|c|c|c|}
\hline \multirow{3}{*}{$\begin{array}{l}\text { Hari, } \\
\text { Tanggal }\end{array}$} & \multicolumn{3}{|c|}{ (LV) } & \multirow{3}{*}{$\begin{array}{c}(\mathrm{HV}) \\
1,2\end{array}$} & \multirow{2}{*}{\multicolumn{3}{|c|}{$\begin{array}{c}(\mathrm{MC}) \\
0,25\end{array}$}} & \multirow{3}{*}{$\begin{array}{c}\mathrm{Q} \\
\mathrm{smp} / \mathrm{ja} \\
\mathrm{m}\end{array}$} \\
\hline & & 1,0 & & & & & & \\
\hline & waktu & & LV & & HV & & MC & \\
\hline \multirow{2}{*}{$\begin{array}{l}\text { Sabtu, } \\
15 \\
\text { Desemb } \\
\text { er } 2018\end{array}$} & $\begin{array}{c}17.00- \\
18.00\end{array}$ & 1,0 & 601 & 1,2 & 6 & 0,25 & 897 & 832,4 \\
\hline & $\begin{array}{c}16.00- \\
17.00\end{array}$ & 1,0 & 690 & 1,2 & 21 & 0,25 & $\begin{array}{c}127 \\
5\end{array}$ & 1033 \\
\hline
\end{tabular}


3. Hambatan Samping

Hasil Perhitungan Frekuensi Berbobot Hambatan Samping Jalan Dr. Angka Purwokerto Kondisi Existing dapat dilihat pada Tabel 3, sedangkan Hasil Perhitungan Frekuensi Berbobot Hambatan Samping Jalan Dr. Angka Purwokerto Kondisi Baru arah Barat - Timur dapat dilihat pada Tabel 4. Hasil Perhitungan Frekuensi Berbobot Hambatan Samping Jalan Dr. Angka Purwokerto Kondisi Baru arah Barat - Timur dapat dilihat pada Tabel 5 dan Hasil Perhitungan Frekuensi Berbobot Hambatan Samping Jalan Dr. Angka Purwokerto Kondisi Baru arah Timur - Barat dapat dilihat pada Tabel 6.

Tabel 3. Hasil Perhitungan Frekuensi Berbobot Hambatan Samping Jalan Dr. Angka Purwokerto Kondisi Existing.

\begin{tabular}{llcccc}
\hline & & & Faktor & Frekuensi & Faktor \\
Periode & \multicolumn{1}{c}{ Tipe Kejadian } & Simbol & Bobot & Kejadian & Berbobot \\
\hline & Kendaraan parkir & KP & 1,0 & 145 & 145 \\
Sabtu, 15 & Pejalan kaki & PK & 0,5 & 158 & 79 \\
Desember & Kendaraan tak & UM & 0,4 & 69 & 27,6 \\
2018 & bermotor & MK & 0,7 & 199 & 139,3 \\
$12.00-$ & Kendaraan keluar & & & & \\
13.00 & masuk & & & & 390,9 \\
\hline \multicolumn{1}{c}{ TOTAL } \\
\hline
\end{tabular}

Tabel 4. Hasil Perhitungan Frekuensi Berbobot Hambatan Samping Jalan Dr. Angka Purwokerto Kondisi Baru arah Barat - Timur

\begin{tabular}{|c|c|c|c|c|c|}
\hline Periode & Tipe Kejadian & Simbol & $\begin{array}{l}\text { Faktor } \\
\text { Bobot }\end{array}$ & $\begin{array}{l}\text { Frekuensi } \\
\text { Kejadian }\end{array}$ & $\begin{array}{l}\text { Faktor } \\
\text { Berbobot }\end{array}$ \\
\hline & Kendaraan parkir & KP & 1,0 & 22 & 22 \\
\hline Sabtu, 15 & Pejalan kaki & PK & 0,5 & 28 & 14 \\
\hline Desember & Kendaraan tak & UM & 0,4 & 28 & 11,2 \\
\hline 2018 & bermotor & MK & 0,7 & 94 & 65,8 \\
\hline \multirow[t]{2}{*}{$\begin{array}{l}17.00- \\
18.00\end{array}$} & $\begin{array}{l}\text { Kendaraan keluar } \\
\text { masuk }\end{array}$ & & & & \\
\hline & TOTAL & & & & 113 \\
\hline
\end{tabular}

Tabel 5. Hasil Perhitungan Frekuensi Berbobot Hambatan Samping Jalan Dr. Angka Purwokerto Kondisi Baru arah Timur - Barat

\begin{tabular}{lllccc}
\hline \multirow{2}{*}{ Periode } & \multicolumn{1}{c}{ Tipe Kejadian } & Simbol & $\begin{array}{c}\text { Faktor } \\
\text { Bobot }\end{array}$ & $\begin{array}{c}\text { Frekuensi } \\
\text { Kejadian }\end{array}$ & $\begin{array}{c}\text { Faktor } \\
\text { Berbobot }\end{array}$ \\
\hline Sabtu, 15 & Kendaraan parkir & KP & 1,0 & 20 & 20 \\
Desember & Pejalan kaki & PK & 0,5 & 14 & 7 \\
2018 & Kendaraan tak bermotor & UM & 0,4 & 20 & 8 \\
$16.00-17.00$ & Kendaraan keluar masuk & MK & 0,7 & 71 & 49,7 \\
\hline \multicolumn{2}{c}{ TOTAL } & & & 84,7 \\
\hline
\end{tabular}


4. Kecepatan Arus Bebas

a. Kecepatan arus bebas dasar $\left(F_{v o}\right)$, untuk jalan empat lajur dua arah (4/2 D) diketahui nilai kecepatan arus bebas dasar untuk kendaraan tinggi (LV) sebesar $57 \mathrm{~km} / \mathrm{jam}$.

b. Faktor penyesuaian kecepatan arus bebas untuk ukuran kota $\left(\mathrm{FFV}_{\mathrm{cs}}\right)$ dengan jumlah penduduk ukuran kota 1,0 - 3,0 juta . didapat nilai faktor penyesuaian kota sebesar 1,00.

c. Faktor penyesuaian kecepatan arus bebas akibat hambatan samping $\left(\mathrm{FFV}_{\mathrm{SF}}\right)$ dengan tipe jalan 4 lajur dua arah tidak terbagi (4/2 D), kelas hambatan samping untuk arah barat - timur (113 kejadian/200m/jam) - arah timur - barat $(84,7$ kejadian $/ 200 \mathrm{~m} / \mathrm{jam}$ ) dan lebar bahu $<1,00 \mathrm{~m}$ (karena digunakan sebagai parkir) didapat nilai faktor penyesuaian akibat hambatan samping $\left(\mathrm{FFV}_{\mathrm{SF}}\right)$ sebesar 0,97.

d. Faktor penyesuaian akibat lebar jalur lintas $\left(\mathrm{FV}_{\mathrm{W}}\right)$ dengan tipe jalan empat lajur dua arah tidak terbagi, lebar efektif jalur lalulintas $\left(\mathrm{W}_{\mathrm{C}}\right) 3.00 \mathrm{~m}$, (karena masingmasing sisi jalan digunakan juga untuk parkir sehingga bahu efektif 1,00 m), didapat nilai faktor penyesuaian akibat lebar jalur lalu lintas $\left(\mathrm{FV}_{\mathrm{W}}\right)$ sebesar -4 $\mathrm{km} / \mathrm{jam}$. Setelah faktor-faktor di atas diketahui maka kecepatan arus bebas dapat dicari dengan menggunakan persamaan 1.2:

$$
\begin{aligned}
\mathrm{FV} & =\left(\mathrm{FV}_{\mathrm{O}}+\mathrm{FV}_{\mathrm{W}}\right) \times \mathrm{FFV}_{\mathrm{SF}} \times \mathrm{FFV}_{\mathrm{CS}} \\
& =(57-4) \times 0,97 \times 1,00 \\
& =51,41 \mathrm{~km} / \mathrm{jam}
\end{aligned}
$$

Dari hasil perhitungan kecepatan arus bebas diatas diperoleh bahwa kecepatan arus bebas untuk kendaraan ringan pada ruas Jl. Dr Angka Purwokerto pada saat jam puncak untuk kondisi jalan baru yaitu sebesar $51,41 \mathrm{~km} / \mathrm{jam}$. Artinya jarak yang dapat ditempuh selama 1 jam adalah 51,41 km. Kecepatan arus bebas kendaraan ringan untuk dua kondisi

Kondisi existing : $48,51 \mathrm{~km} / \mathrm{jam}$

Kondisi baru : $51,41 \mathrm{~km} / \mathrm{jam}$

5. Kapasitas

a. Kapasitas dasar (Co), untuk tipe jalan empat lajur tak terbagi diperoleh kapasitas dasar sebesar $1650 \mathrm{smp} / \mathrm{jam}$ untuk total dua arah.

b. Faktor penyesuaian kapasitas akibat lebar jalur lalu lintas $\left(\mathrm{FC}_{\mathrm{W}}\right)$, dengan lebih efektif jalur lalu lintas $\left(\mathrm{W}_{\mathrm{C}}\right)=3 \mathrm{~m}$, didapat nilai untuk faktor penyesuaian kapasitas akibat lebar jalur lalu lintas sebesar 0,92.

c. Faktor penyesuaian kapasitas akibat pemisah arah (FCsp), didasarkan pada pemisah arah (50-50), didapat nilai faktor penyesuaian kapasitas akibat pemisahan arah sebesar 1,00 .

d. Faktor penyesuaian kapasitas akibat hambatan samping $\left(\mathrm{FC}_{\mathrm{SF}}\right)$ untuk tipe jalan empat lajur tak terbagi, kelas hambatan samping sedang dan lebar bahu efektif $1,00 \mathrm{~m}$, didapat nilai faktor penyesuaian kapasitas akibat hambatan samping sebsar 0,95 .

e. Faktor penyesuaian kapasitas untuk ukuran kota $\left(\mathrm{FC}_{\mathrm{CS}}\right)$ dengan didasarkan pada jumlah penduduk antara 1,0-3,0 juta penduduk didapat nilai faktor penyesuaian kapasitas untuk ukuran kota sebesar 1,00.

f. Setelah semua faktor diatas nilainya diketahui, maka nilai kapasitas dapat ditentukan dengan menggunakan persamaan 1.3:

$$
\begin{aligned}
\mathrm{C} & =\text { Co } \times \mathrm{FCw} \times \mathrm{FCsp} \times \mathrm{FCSF} \times \mathrm{FCcs} \\
& =1650 \times 0,92 \times 1,00 \times 0,95 \times 1,00 \\
& =1442,1 \mathrm{smp} / \mathrm{jam}
\end{aligned}
$$


Perbandingan Kapasitas JalanDerajat Kejenuhan dapat dilihat pada Tabel 6.

Tabel 6. Perbandingan Kapasitas JalanDerajat Kejenuhan

\begin{tabular}{cc}
\hline $\begin{array}{c}\text { Kondisi Ruas } \\
\text { Jalan }\end{array}$ & Kapasitas (smp/jam) \\
\hline Existing & 1337,7 \\
Baru & 1442,1 \\
\hline
\end{tabular}

Nilai derajat kejenuhan pada ruas Jalan Dr. Angka Purwokerto kondisi baru dapat diketahui dengan cara membagi volume lalu lintas (Q) dengan nilai kapasitas jalan (C) yang telah didapat, sebagai berikut:

$$
\begin{aligned}
\mathrm{DS} & =\mathrm{Q} / \mathrm{C} \\
& =832,4 / 1442,1 \\
& =0,57(\mathrm{~B}-\mathrm{T}) \\
\mathrm{DS} & =\mathrm{Q} / \mathrm{C} \\
& =1033 / 1442,1 \\
& =0,71(\mathrm{~T}-\mathrm{B})
\end{aligned}
$$

Perbandingan Derajat Kejenuhan dapat dilihat pada Tabel 7.

\begin{tabular}{cc} 
Tabel 7. Perbandingan Derajat Kejenuhan \\
\hline Kondisi Ruas Jalan & Derajat Kejenuhan \\
\hline Existing & 1,56 \\
Baru & $0,57(\mathrm{~B}-\mathrm{T})$ \\
& $0,71(\mathrm{~T}-\mathrm{B})$ \\
\hline
\end{tabular}

6. Kecepatan dan waktu tempuh

Kecepatan arus bebas kendaraan ringan untuk dua kondisi dapat dilihat pada Tabel 8.

Tabel 8. Kecepatan arus bebas kendaraan ringan untuk dua kondisi

\begin{tabular}{lc}
\hline Kondisi Ruas jalan & $\begin{array}{c}\text { Kecepatan Tempuh } \\
\text { (detik) }\end{array}$ \\
\hline Existing & 14,84 \\
Baru & 14,00 \\
\hline
\end{tabular}

7. Tingkat Pelayanan

Setelah analisa dilakukan, dapat diketahui indeks tingkat pelayanan yang dapat dilihat pada Tabel 9.

Tabel 9. Indeks tingkat pelayanan

\begin{tabular}{lcclc}
\hline \multicolumn{1}{c}{ Kondisi jalan } & $\begin{array}{c}\text { Volume Lalu } \\
\text { Lintas } \\
(\text { smp/jam })\end{array}$ & $\begin{array}{c}\text { Kapasitas } \\
(\text { smp/jam })\end{array}$ & $\begin{array}{c}\text { Kecepatan } \\
(\mathrm{km} / \mathrm{jam})\end{array}$ & $\begin{array}{c}\text { Indeks } \\
\text { Pelayanan } \\
\text { Jalan }\end{array}$ \\
\hline $\begin{array}{l}\text { Existing } \\
\begin{array}{l}\text { UD) } \\
\text { Baru } \\
(4 / 2 \text { D })\end{array}\end{array}$ & 2099 & 1337,7 & 48 & $\mathrm{~F}$ \\
& 832,4 & 1442,1 & 51 & $\mathrm{C}$ \\
\hline
\end{tabular}




\section{Pengaruh Median Terhadap Ruas Jalan Dr. Angka}

Jalan Dr. Angka Purwokerto merupakan jalan yang cukup vital dengan tipe jalan empat lajur dua arah tanpa pemisah arah (median) dari kondisi ruas jalan yang cukup padat lalu lintas tersebut maka pemisah arah (median) dapat diterapkan guna meningkatkan kapasitas dan kinerja ruas jalan itu. Berdasarkan analisa yang telah dilakukan terjadi perubahan kinerja dari masing-masing kondisi jalan Dr. Angka yang diakibatkan oleh ada atau tidaknya pemisah arah (median).

Hasil analisa jalan Dr. Angka kondisi existing atau jalan tanpa median didapatkan data kejenuhan 1,56 dimana nilai tersebut melebihi batas kejenuhan yang diijinkan menurut MKJI 1997 yaitu 0,75. Sehingga kondisi ruas jalan Dr. Angka dengan nilai DS tersebut, berarti bahwa kondisi arus lalu lintasnya tidak stabil dengan kepadatan yang tinggi. Berbeda dengan jalan Dr. Angka kondisi baru, karena adanya pemisah arah (median) yang membatasi dua arah yang berlawanan, menimbulkan rendahkan kepadatan lalu lintas pada ruas jalan tersebut. Berdasarkan analisa pada kondisi jalan Dr. Angka kondisi baru lebih baik dibandingkan dengan kondisi existing.

\section{KESIMPULAN}

Kapasitas jalan untuk kondisi ruas jalan Dr. Angka Purwokerto sebagai berikut:

Kondisi Existing

Kondisi Baru

$$
\begin{aligned}
& : 1337,7 \text { (smp/jam) } \\
& : 1442,1 \text { (smp/jam) (B-T) } \\
& : 1442,1 \text { (smp/jam) (T-B) }
\end{aligned}
$$

Tingkat pelayanan pada jalan Dr. Angka Purwokerto mengalami peningkatan akibat perubahan geometrik dan perbaikan jalan tersebut. Tingkat pelayanan yang terjadi pada kondisi ruas jalan Dr. Angka Purwokerto antara lain:

- Kondisi Existing dengan kategori pelayanan $\mathrm{F}$

- Kondisi Baru dengan kategori pelayanan C (B-T)

- Kondisi Baru dengan kategori pelayanan C (T-B)

Kinerja jalan pada ruas jalan Dr. Angka Purwokerto adalah :

- Kondisi Existing keadaan lalu lintas kondisi kritis dengan DS = 1,56

- Kondisi Baru keadaan lalu lintas kondisi stabil dengan DS = 0,57 (B-T)

- Kondisi Baru keadaan lalu lintas kondisi stabil dengan DS = 0,71 (T-B)

Jalan Dr. Angka Purwokerto yang ada pemisah arah (median) lebih rendah kepadatan arus lalu lintasnya dan dari segi pelayanan lebih baik.

\section{DAFTAR PUSTAKA}

Akbar,dkk, 2017, Evaluasi Kinerja Jalan Terhadap Rencana Pembangunan Jalan Dua Lajur, Universitas Malikussaleh, Banda Aceh

Direktorat Jendral Bina Marga, 1997, Manual Kapasitas Jalan Indonesia (MKJI), Sweroad dan PT. Bina Karya, Jakarta

UU No. 38 Tahun 2004 Tentang Jalan

Direktorat BSLLAK, 1999, Rekayasa Lalu Lintas Pedoman Perencanaan dan Pengoperasian Lalu Lintas di Wilayah Perkotaan

Morlock, E. K. 1991. Perencanaan Teknik dan Perencanaan Transportasi (Terjemahan). Erlangga . Jakarta

Morlok, K.,1995, Pengantar Teknik dan Perencanaan Transportasi, Erlangga, Jakarta

Muhtadi, A., 2010, Analisi Kapasitas Tingkat pelayanan Kinerja Dan Pengaruh Pemberian Median Jalan, Neutron, Jawa Timur 
Oglesby, H., Hicks, R.,et al., 1999, Teknik Jalan Raya, Ir.Purwo Setianto, Erlangga, Jakarta Putranto, S., 2008, Rekayasa Lalu Lintas, Indeks, Jakarta

Tamin, O.Z \& Nahdalina. Analisis Dampak Lalu Lintas ( ANDALL).

Titirlobi,Indri,Angelina,dkk,2016. Analisa Kinerja Ruas Jalan Hasanuddin Kota Manado, Fakultas Tehnik Jurusan Sipil Universitas Sam Ratulagi, Jurnal Sipil Statik Vol.4 No. 7 